\title{
Green Concrete from Sustainable Recycled Coarse Aggregates: Mechanical and Durability Properties
}

\author{
Neeraj Jain, Mridul Garg, and A. K. Minocha \\ EST Division, CSIR-Central Building Research Institute, Roorkee 247667, India \\ Correspondence should be addressed to Neeraj Jain; neerajest@rediffmail.com \\ Received 3 November 2014; Accepted 15 January 2015 \\ Academic Editor: Brajesh Dubey
}

Copyright ( 2015 Neeraj Jain et al. This is an open access article distributed under the Creative Commons Attribution License, which permits unrestricted use, distribution, and reproduction in any medium, provided the original work is properly cited.

\begin{abstract}
Present investigations deal with the development of green concrete (M 30 grade) using recycled coarse aggregates for sustainable development. Characterization of recycled coarse aggregates showed that physical and mechanical properties are of inferior quality and improvement in properties was observed after washing due to removal of old weak mortar adhered on its surface. The influence of natural coarse aggregates replacement (50 and 100\%) with recycled coarse aggregate on various mechanical and durability properties of hardened concrete were discussed and compared with controls at different w/c ratio. Improvements in all the engineering properties of hardened concrete were observed using washed recycled coarse aggregates. The compressive strength of 28 -day hardened concrete containing $100 \%$ washed recycled aggregate was slightly lower (7\%) than concrete prepared with natural aggregates. Water absorption, carbonation, and rapid chloride penetration test were conducted to assess the durability of the concrete. Concrete was found moderately permeable for chloride ions penetration and no carbonation was observed in all the concrete mixes studied.
\end{abstract}

\section{Introduction}

The environmental problem arising from unscientific and indiscriminate disposal of municipal solid waste (MSW) is a real menace for the whole society. These wastes are increasing day by day due to increase in population, urbanization, and industrialization. The characterization of MSW shows that it contains about $55-65 \%$ of compostable material, $25-35 \%$ of dry/recyclable materials, and $15-20 \%$ of inert material [1]. In India, the amount of MSW generated per capita is estimated to increase at a rate of $1-1.33 \%$ annually $[2,3]$. The provision of land filling for MSW management is not a primary solution; the technology and science has to play the major role in the successful implementation of waste management. It needs paradigm shift in vision in managerial concept to focus more on waste minimization or complete recycling of waste rather than getting rid of land filling. As far as possible, the landfill step has to be omitted from the mind by giving more emphasis on $100 \%$ recycling of waste. Recycling and recovery (treatment/processing) plays a large role in solid waste management. The inert waste is the result of enormous construction and demolition activities and it mainly consists of concrete, bricks, stones pebbles, and so forth. The central pollution Control Board (CPCB), India, has estimated the solid waste generation about 48 million tonnes per annum of which $25 \%$ are from construction industry [1]. The total amount of waste is estimated to be 12-14.7 million tonnes every year. The increasing amount of demolition waste has created a significant impact on environment and society and its management is a growing concern all over the world. Factors such as sustainability, economy, shortage of land for disposal, and good quality of raw materials for construction make it imperative that construction and demolition waste should be properly recycled. The demolition waste which was previously thought of nonusable now has been proved by previous studies that it could be utilized completely not only as recycled aggregate for production of environmental friendly concrete, but also for a number of other applications in construction [4-8]. Utilization of recycled aggregate recycled aggregate solves the disposal problem and also reduces the use of natural resources in construction industry and thus contributes to the environmental protection by reducing 
TABle 1: Typical composition of ordinary Portland cement.

\begin{tabular}{cccccccccccc}
\hline & \multicolumn{1}{c}{ Chemical composition (\%) } \\
$\mathrm{CaO}$ & $\mathrm{SiO}_{2}$ & $\mathrm{Al}_{2} \mathrm{O}_{3}$ & $\mathrm{Fe}_{2} \mathrm{O}_{3}$ & $\mathrm{SO}_{3}$ & $\mathrm{MgO}$ & $\mathrm{K}_{2} \mathrm{O}$ & $\mathrm{Na}_{2} \mathrm{O}$ & $\mathrm{TiO}_{2}$ & $\mathrm{BaO}_{2}$ & $\mathrm{P}_{2} \mathrm{O}_{5}$ & $\mathrm{Others}$ \\
\hline 64.34 & 19.90 & 4.30 & 4.24 & 2.88 & 2.04 & 1.05 & 0.31 & 0.33 & 0.25 & 0.13 & 0.23 \\
\hline
\end{tabular}

carbon footprint due to less crushing. The use of recycled aggregate for the production of concrete involves breaking demolished concrete into materials with specified size and quality. These materials can then be combined to produce aggregate of a predetermined grading and hence can be used in concrete.

Production and utilization of recycled aggregate are common practice in construction industries of several countries like USA [9], Australia [10], and Japan [11]. According to 2010 European Aggregate Association Annual Review report [12], Germany is the greatest producer of recycled aggregate recycled aggregate, with a production of about 60 million tonnes followed by UK, Netherlands, and France with about 49, 20, and 17 million tonnes, respectively. Few countries have prepared guidelines and published standards for use of recycled aggregate in concrete like Germany (DIN 4226-100), Japan (JIS A 5021: 2011 and JIS A 5023: 2012), and China (DG/TJ07-008) [13-16]. The work Bureau Technical Circular (WBTC) published the specifications of recycled aggregate in concrete application in public work projects in Hong Kong [17]. Recently BS EN 12620: 2013 has recommended the designations for recycled concrete aggregates (RCA) and recycled aggregate (RA) concreting aggregates for general use [18].

In India, despite availability of huge amount of demolition waste, very few efforts have been done on the utilization of this waste to wealth. Therefore, a systematic study has been undertaken to utilize recycled coarse aggregate as a partial replacement for natural coarse aggregates for development M30 grade concrete. The recycled coarse aggregates have been utilized as such (unwashed) as well as in washed form for comparison purpose with control concrete using natural aggregates. Engineering properties and durability aspects of the hardened concrete prepared with the replacement of natural aggregates with recycled aggregates are discussed.

\section{Materials and Methods}

2.1. Cement and Aggregates. Ordinary Portland cement (OPC) of 43 Grade conforming to IS: 8112:1989 [19] was utilized as binder with surface area of $3220 \mathrm{~cm}^{2} / \mathrm{g}$ and specific gravity of 3.14. Typical chemical composition of OPC is given in Table 1. Samples of demolition waste were collected from MSW processing plant of Municipal Corporation of Delhi, India, which consists of concrete, bricks, stones, gravel, silt, and so forth. The segregated concrete waste was crushed in a jaw crusher to obtain a well graded aggregate for maximum $20 \mathrm{~mm}$ size as per IS 383: 1970 [20]. Unwashed and washed recycled aggregates used in the present studies were tested for various physical and mechanical properties as per IS 2386 : 1963 [21].
To obtain the washed aggregate, presoaking of recycled aggregates in water for $24 \mathrm{~h}$ was carried out for removal of clay, girt, dust, and so forth followed by two times washing manually for removal of adhered mortar. The locally available unwashed natural crushed stone, generally of quartzite type, has been used as natural coarse aggregate of maximum $20 \mathrm{~mm}$ size satisfying the grading requirements of IS 383: 1970 [20] and tested as per IS 2386: 1963 [21]. Two different sizes of $20 \mathrm{~mm}$ and $10 \mathrm{~mm}$ of coarse aggregates have been used in equal proportions throughout the experimental studies in surface saturated dry conditions to maintain a desired concrete slump and to avoid high water absorption by recycled aggregate $[22,23]$. Local Ganga river sand graded as per IS 383: 1970 [20] was taken as fine aggregates for use in natural and recycled aggregate concrete and it was tested as per IS: $2386: 1963$. The commercially available polycarboxylic ether based super plasticizer Glenium 51 having a specific gravity of 1.08 was used as chemical admixture in order to attain the workability of concrete.

2.2. Concrete Mix Proportions. Concrete mix proportions of M30 grade were designed as per IS 10262: 2009 [24] to achieve a target compressive strength of $38.25 \mathrm{MPa}$ at the age of 28 days. Mix design using natural aggregates (R0A, R0B, and R0C), natural aggregate replaced $50 \%\left(R_{U} 50 A, R_{U} 50 B\right.$, and $\left.R_{U} 50 C\right)$ and $100 \%\left(R_{U} 100 A, R_{U} 100 B\right.$ and $\left.R_{U} 100 C\right)$ by unwashed recycled aggregate as well as with $100 \%$ washed recycled aggregates $\left(\mathrm{R}_{\mathrm{W}} 100 \mathrm{C}\right)$ was carried out to get a slump of $25-50 \mathrm{~mm}$ with fixed cement content of $360 \mathrm{~kg} / \mathrm{m}^{3}$ as shown in Table 2. The properties of recycled aggregates concrete were compared with control concrete made from natural aggregates.

2.3. Mixing, Casting, and Curing of Concrete. Two-stage mixing was performed in a rotating drum mixer as per procedure described by Ismail and Ramli [25]. In first stage, mixing procedure involved adding both coarse and fine aggregates into the drum mixer and dry mixed for 30 second to allow aggregates to mix homogeneously. Secondly, the first half portion of the mixing water was added into the mixer and the mixing continued for another $2 \mathrm{~min}$. The mixer was then stopped for $3 \mathrm{~min}$ to facilitate the absorption of water into aggregates. The cement was added and the mixer continued for another half minute. Finally, the remaining half of the mixing water was added and further mixing was performed for approximately $2 \mathrm{~min}$ more. Mixing procedure and time have been kept constant for all the mixes. After completion of the mixing, slump cone test was performed as per IS: 1199: 1959 [26] to determine the workability of the mixes. To finalize the mix proportion, casting of cubes $(150 \times 150 \times$ $150 \mathrm{~mm})$, cylinders (150 mm diameter $\times 300 \mathrm{~mm}$ height $)$ and 
TABLE 2: Mix proportions of concrete per cubic meter using natural and recycled coarse aggregates.

\begin{tabular}{|c|c|c|c|c|c|c|}
\hline Mixes & Cement (kg) & Coarse aggregate $(\mathrm{kg})$ & Fine aggregate $(\mathrm{kg})$ & Water $(\mathrm{kg} / \mathrm{L})$ & Superplasticizer (\%) & Slump (mm) \\
\hline R0A & 360 & 1251 & 658 & 162 & - & 27 \\
\hline $\mathrm{R}_{\mathrm{U}} 50 \mathrm{~A}$ & 360 & 1251 & 658 & 162 & - & 22 \\
\hline $\mathrm{R}_{\mathrm{U}} 100 \mathrm{~A}$ & 360 & 1251 & 658 & 162 & 一 & 18 \\
\hline R0B & 360 & 1251 & 658 & 162 & 0.25 & 34 \\
\hline $\mathrm{R}_{\mathrm{U}} 50 \mathrm{~B}$ & 360 & 1251 & 658 & 162 & 0.25 & 32 \\
\hline $\mathrm{R}_{\mathrm{U}} 100 \mathrm{~B}$ & 360 & 1251 & 658 & 162 & 0.25 & 30 \\
\hline R0C & 360 & 1251 & 658 & 151 & 0.25 & 32 \\
\hline $\mathrm{R}_{\mathrm{U}} 50 \mathrm{C}$ & 360 & 1251 & 658 & 151 & 0.25 & 30 \\
\hline $\mathrm{R}_{\mathrm{U}} 100 \mathrm{C}$ & 360 & 1251 & 658 & 151 & 0.25 & 28 \\
\hline $\mathrm{R}_{\mathrm{W}} 100 \mathrm{C}$ & 360 & 1251 & 658 & 151 & 0.25 & 32 \\
\hline
\end{tabular}

prisms $(100 \times 100 \times 500 \mathrm{~mm})$ was carried out in two phases for determination of mechanical and durability properties.

In first phase, casting of cubes was carried out as per mix proportion shown in Table 2 using natural and 50 and $100 \%$ recycled coarse aggregates at w/c ratio of 0.45 without and with super plasticizer $(0.25 \%)$, while, in second phase, casting of cubes, cylinder and prism was carried out using natural and unwashed recycled aggregates (50\% and $100 \%)$ at reduced w/c ratio (0.42) keeping the dose of super plasticizer constant (Table 2). To evaluate washed aggregate performance in hardened concrete, $100 \%$ washed recycled coarse aggregate $\left(\mathrm{R}_{\mathrm{W}} 100 \mathrm{C}\right)$ was also used for casting of concrete cubes using similar mix proportion (Table 2) as in case of unwashed recycled coarse aggregates $\left(R_{U} 100 \mathrm{C}\right)$ considering it as final mix. All hardened concrete specimens were cast in laboratory condition, demoulded at $24 \mathrm{~h}$ after casting, immersed in water at $27 \pm 2^{\circ} \mathrm{C}$ for curing, and then tested for engineering properties after their respective hydration periods.

2.4. Density of Hardened Concrete. The bulk density of $150 \times 150 \times 150 \mathrm{~mm}$ cubes of hardened concrete $\left(\mathrm{R} 0 \mathrm{C}, \mathrm{R}_{\mathrm{U}} 50 \mathrm{C}\right.$, $\mathrm{R}_{\mathrm{U}} 100 \mathrm{C}$, and $\mathrm{R}_{\mathrm{W}} 100 \mathrm{C}$ ) was determined at 28-day curing period as per method described in ASTM C 642 [27].

2.5. Mechanical Properties of Concrete. Mechanical properties like compressive strength and split tensile strength were determined as per procedure described in IS: 516: 1959 [28]. The compressive strength was determined on 3-, 7-, and 28day curing period for cubes and on 28th day for cylinders. Split tensile strength of cylinders was determined according to IS: 5816: 1999 [29] on 7- and 28-day curing period. The flexural test was conducted on prisms at 28-day curing period in accordance with IS: 516:1959. Air dried specimens were tested to determine the respective strength on a $1000 \mathrm{kN}$ UTM at constant rate of loading and the average of three values of specimens tested is reported in the results.

2.6. Durability Properties of Concrete. The durability of the hardened concrete using was studied by (i) performance in water, (ii) carbonation, and (iii) rapid chloride ion penetration.
2.6.1. Performance in Water. Water absorption is the measure of permeability and porous nature of hardened concrete. Water absorption of 28 days hardened concrete cubes (R0C, $\mathrm{R}_{\mathrm{U}} 50 \mathrm{C}, \mathrm{R}_{\mathrm{U}} 100 \mathrm{C}$, and $\mathrm{R}_{\mathrm{W}} 100 \mathrm{C}$ ) was determined as per method described in ASTM C 642 [27]. Oven dried cubes were allowed to cool at room temperature and then immersed in water for $48 \mathrm{~h}$, air dried, and weighed to calculate the percentage of water absorption.

2.6.2. Carbonation Test. Carbonation of concrete is the process by which carbon dioxide from air penetrates into concrete through pores and reacts with calcium hydroxide to form calcium carbonates responsible for lower $\mathrm{pH}$. An accelerated carbonation test was carried out according to Papadakis et al. using carbonation chamber [30]. Air dried specimens of cubes (R0C, $R_{U} 50 C, R_{U} 100 C$, and $R_{W} 100 C$ ) were sealed with an epoxy resin coating on all four sides and kept in chamber for 28 days. A temperature of $20^{\circ} \mathrm{C}$, relative humidity $65 \%$ and $\mathrm{CO}_{2}$ concentration $20 \%$ were maintained in the carbonation chamber during the test. After 28 days, all the cubes were fractured in two halves and observed for carbonation by phenolphthalein test as described in RILEM CPC-18 [31]. Phenolphthalein was prepared as a $1 \%$ solution in $70 \%$ ethyl alcohol and the solution is sprayed onto the concrete surface which has been cleaned of dust and loose particles. Alkaline nature of the concrete was observed due to the change in colour of phenolphthalein. If no coloration occurs, carbonation has taken place and the depth of the carbonated surface layer can be measured.

2.6.3. Rapid Chloride Penetration Test. The rapid chloride penetration test (RCPT) is the fastest method conducted to assure the permeability of the concrete as durability aspects. It is used to study the resistance of concrete to chloride ion migration in the pores. RCPT was carried out following the standard procedure described in ASTM C1202 (1997) [32] for the hardened concrete cylinder of R0C, $R_{U} 50 C, R_{U} 100 C$, and $\mathrm{R}_{\mathrm{W}} 100 \mathrm{C}$ mix. Sodium hydroxide solution $(0.3 \mathrm{~N} \mathrm{NaOH})$ and sodium chloride solution ( $3 \% \mathrm{NaCl}$ by mass) were placed in the chambers on two sides of concrete specimen $(100 \mathrm{~mm}$ diameter and $50 \mathrm{~mm}$ thickness cut from cylinder) and a direct current voltage of $60 \mathrm{~V}$ was applied. The current passing through the concrete specimen was monitored every thirty 
TABLE 3: Physical properties of natural and recycled coarse aggregate.

\begin{tabular}{lcccccc}
\hline & \multicolumn{2}{c}{$\begin{array}{c}\text { Natural aggregate } \\
\text { Parameters }\end{array}$} & \multicolumn{4}{c}{ Recycled aggregate } \\
& $20 \mathrm{~mm}$ & $10 \mathrm{~mm}$ & $20 \mathrm{~mm}$ & $10 \mathrm{~mm}$ & $20 \mathrm{~mm}$ & $10 \mathrm{~mm}$ \\
\hline $\begin{array}{l}\text { Fineness } \\
\text { modulus }\end{array}$ & 6.95 & 6.44 & 6.89 & 6.13 & 6.77 & 6.06 \\
$\begin{array}{l}\text { Specific } \\
\text { gravity }\end{array}$ & 2.67 & 2.66 & 2.40 & 2.36 & 2.50 & 2.46 \\
$\begin{array}{l}\text { Bulk density } \\
(\mathrm{kg} / \mathrm{L})\end{array}$ & 1.564 & 1.557 & 1.436 & 1.350 & 1.440 & 1.365 \\
\hline
\end{tabular}

minutes over a six-hour period and the total charge passed (coulombs) was computed.

\section{Results and Discussion}

3.1. Properties of Aggregates. The particle size distribution of natural and recycled coarse aggregate has been shown in Figure 1 along with minimum and maximum limits of grading specified in IS: 383: 1970. A perusal of Figure 1 show that all the aggregates are properly graded and satisfy the IS: 383 requirements. It is also observed (Figure 1) that both washed and unwashed recycled coarse aggregates are finer than natural coarse aggregates and the same is supported by low values of fineness modulus (FM) shown in Table 3 for 20 and $10 \mathrm{~mm}$ sizes along with physical properties like specific gravity and bulk density. The values shown in Table 3 reveal that there is a marked difference in the properties of natural and recycled coarse aggregates. Recycled aggregate has low specific gravity (7-10\%) and density $(8-14 \%)$ as compared to natural aggregate. It can also be seen from Table 3 that the washed recycled coarse aggregates have relatively less deteriorated properties as compared to unwashed recycled coarse aggregates due to removal of old adhered mortar. The main reason for the low specific gravity and density of $10 \mathrm{~mm}$ size aggregates is old adhered mortar which is light and porous in nature and varies with size and quantity of recycled aggregate [33]. Other physical properties like percent flakiness index, elongation index, and water absorption are shown in Figure 2 which indicates high flakiness and elongation index of recycled coarse aggregates as compared to natural aggregates. The water absorption of natural aggregate was observed to negligible $(0.40 \%)$ as compared to recycled aggregates (3.5-4.70\%). The water absorption of unwashed recycled aggregates was higher $(23-26 \%)$ as compared to washed recycled coarse aggregates.

Further, the mechanical properties like crushing and impact values of recycled aggregate are shown in Figure 3 along with natural aggregates. Figure 3 revealed that the crushing and impact values of unwashed recycled aggregates are higher than natural and washed recycled aggregates. The crushing and impact values of unwashed recycled aggregates were found to be $43-48 \%$ and $9-20 \%$ and $39-41 \%$ and $9-15 \%$ higher than natural and washed recycled aggregates, respectively. The higher crushing and impact values of unwashed

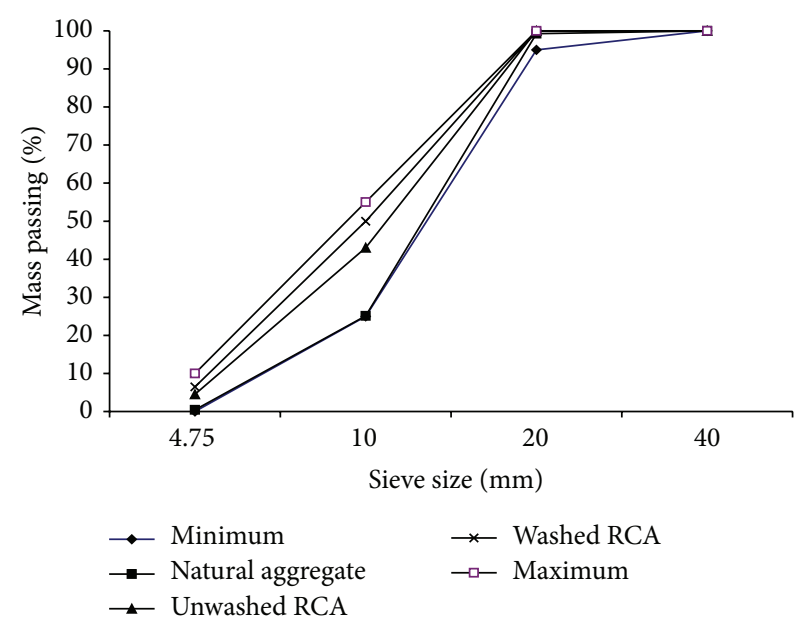

FIGURE 1: Percentage grading of natural and recycled aggregates.

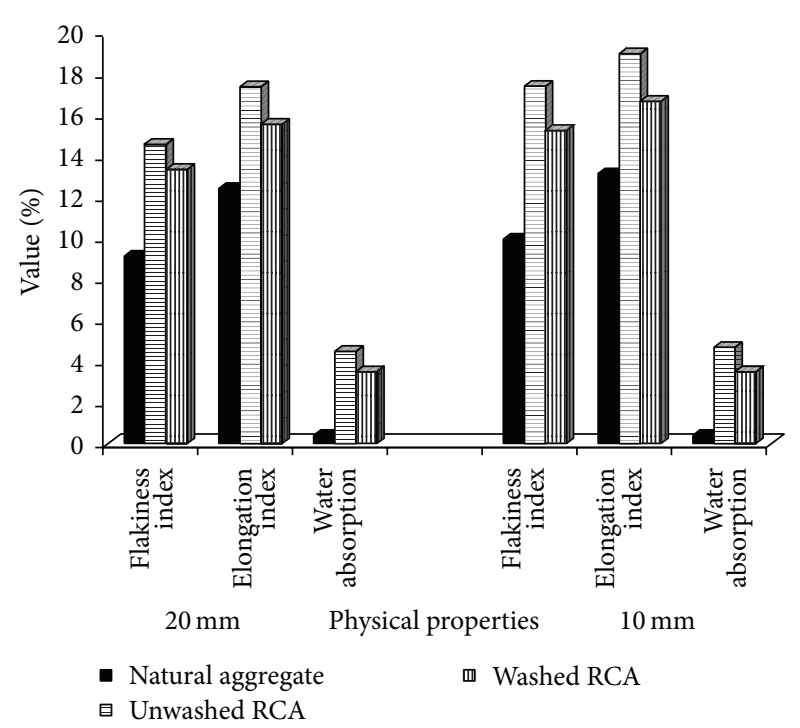

FIgURE 2: Physical properties of natural and recycled aggregates of different sizes.

recycled aggregates are due to the presence of adhered mortars which get removed during testing. Therefore the recycled aggregate may be characterized as inferior quality aggregate by being weaker than the normal aggregate [33, 34]. However, it is also observed that washing with water greatly influences the physical and mechanical properties of recycled coarse aggregate due to removal of the adhered loosely bounded cement mortar. Improvement in density and water absorption of lower size $(10 \mathrm{~mm})$ recycled aggregate is more than large size $(20 \mathrm{~mm})$ aggregate because of presence of higher amount of adhered mortar [25,35]. Thus the loss of adhered mortar is higher in small size aggregate and is responsible for higher density and low water absorption as compared to large size aggregate. Because of the relationship between aggregate density and water absorption [36], the increase in recycled aggregate density results in the significant decrease in waster absorption. Particle size distribution curve 


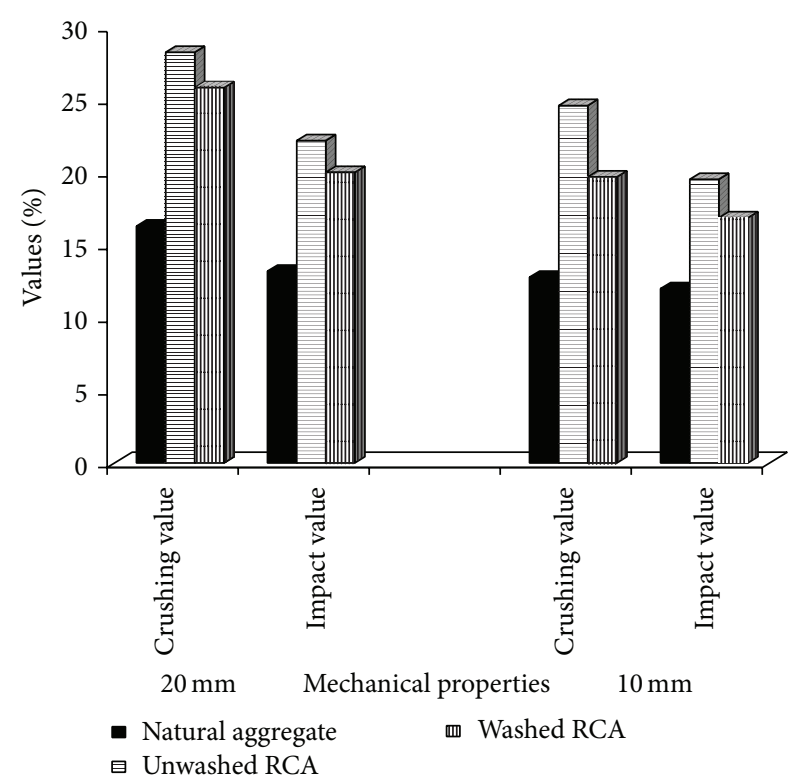

FIGURE 3: Mechanical properties of natural and recycled aggregates of different sizes.

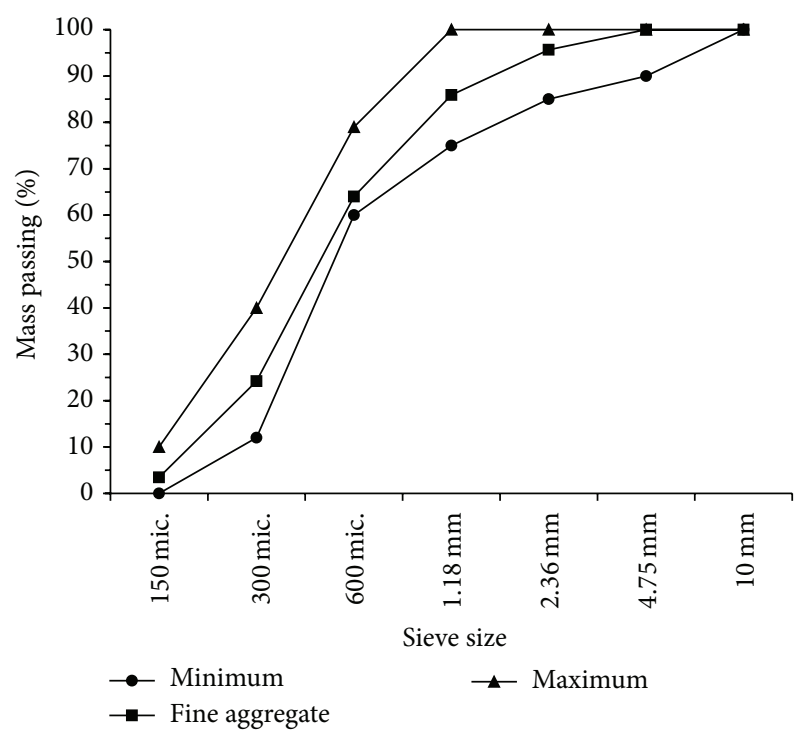

FIGURE 4: Particle size distribution curves of fine aggregate.

of fine aggregates has been shown in Figure 4 and confirms to Zone III is relatively finer as per IS: 383: 1970. Fineness modulus of fine aggregate used was 2.26 and physical properties like specific gravity and water absorption were 2.68 and $0.4 \%$, respectively.

3.2. Mechanical Properties of Concrete. The compressive strength of hardened concrete cubes has been determined on 3-, 7-, and 28-day curing period and results are shown in Figure 5. In general, the results show development of early strength in all the concrete mixes and it was a function of curing period. This may be due to the increased amount of hydration products on prolonged curing period. Further, it is

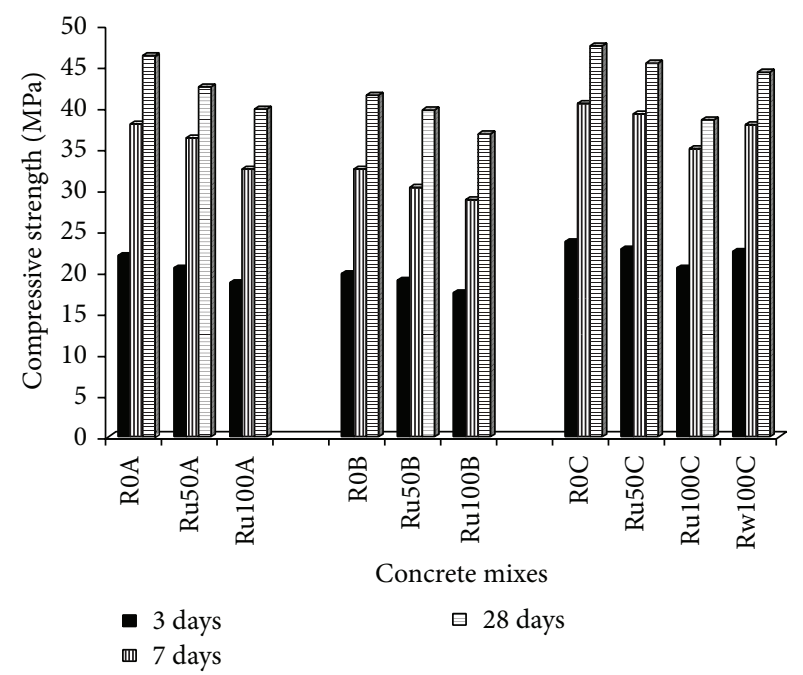

FIGURE 5: Compressive strength of hardened concrete cubes with different curing period.

observed that 3-day strength of mixes recycled aggregates was more or less similar to that of natural aggregates. The mixes $\mathrm{R} 0 \mathrm{~A}, \mathrm{R}_{\mathrm{U}} 50 \mathrm{~A}$, and $\mathrm{R}_{\mathrm{U}} 100 \mathrm{~A}$ with w/c ratio of 0.45 (without super plasticizer) show a maximum strength of 46.3, 42.5, and $39.8 \mathrm{MPa}$, respectively, at 28 days of curing. Although target strength of $38.25 \mathrm{MPa}$ has been achieved by mixes using recycled coarse aggregates, the desired workability has not been achieved as shown in Table 2 due to high water absorption. Therefore, another mix with same w/c ratio using super plasticizer $\left(\mathrm{R} 0 \mathrm{~B}, \mathrm{R}_{\mathrm{U}} 50 \mathrm{~B}\right.$, and $\left.\mathrm{R}_{\mathrm{U}} 100 \mathrm{~B}\right)$ was designed. Good workability was observed in these mixes using super plasticizer (slump 30-34 mm), but the target strength is achieved only by concrete using natural aggregates (R0B) and $50 \%$ unwashed recycled aggregates $\left(R_{U} 50 B\right)$. The 28 -day strength of specimens $R_{U} 50 B$ and $R_{U} 100 B$ is 4.4 and $13.4 \%$ lower than control (R0B). To achieve the target strength by $100 \%$ replacement of unwashed recycled aggregates, mixes $\mathrm{R} 0 \mathrm{C}, \mathrm{R}_{\mathrm{U}} 50 \mathrm{C}$, and $\mathrm{R}_{\mathrm{U}} 100 \mathrm{C}$ are designed at low w/c ratio (0.42) with super plasticizer. It is observed that workability in these mixes was $28-32 \mathrm{~mm}$ and the strength with recycled aggregates concrete is meeting the target strength requirements. The 28-day strength of ROC, $R_{U} 50 \mathrm{C}$, and $\mathrm{R}_{U} 100 \mathrm{C}$ is $47.5,45.4$, and $38.5 \mathrm{MPa}$. The results indicate that the strength of unwashed recycled aggregate concrete is lower than natural aggregates concrete in all mixes and a decrease of $14 \%$ has been observed in 28-day strength with an increase of recycled aggregates content from 50 to $100 \%$. Similar trends have also been reported by earlier workers [37]. The inferior mechanical properties of recycled aggregates are responsible for reduction in strength of the hardened concrete.

For evaluation of washed recycled aggregate concrete strength characteristics, casting with $100 \%$ washed recycled aggregate $\left(\mathrm{R}_{\mathrm{W}} 100 \mathrm{C}\right)$ has also been carried out at final mix composition. The compressive strength of $\mathrm{R}_{\mathrm{W}} 100 \mathrm{C}$ at 3, 7, and 28 days has been shown in Figure 5 which indicates improvement in strength of hardened concrete as compared to $\mathrm{R}_{\mathrm{U}} 100 \mathrm{C}$. The strength of $\mathrm{R}_{\mathrm{W}} 100 \mathrm{C}$ cubes is $12.5 \%$ higher 
TABLE 4: Testing results of hardened concrete cylinders and prisms at different curing period.

\begin{tabular}{|c|c|c|c|c|}
\hline \multirow{2}{*}{ Mixes } & \multirow{2}{*}{$\begin{array}{l}\text { Compressive } \\
\text { strength } \\
(\mathrm{MPa}) \\
28 \text { days }\end{array}$} & \multicolumn{2}{|c|}{ Split tensile strength (MPa) } & \multirow{2}{*}{$\begin{array}{c}\text { Flexural } \\
\text { strength } \\
\text { (MPa) } \\
28 \text { days }\end{array}$} \\
\hline & & 7 days & 28 days & \\
\hline R0C & 33.5 & 2.36 & 2.94 & 4.98 \\
\hline $\mathrm{R}_{\mathrm{U}} 50 \mathrm{C}$ & 32.8 & 2.30 & 2.78 & 4.92 \\
\hline $\mathrm{R}_{\mathrm{U}} 100 \mathrm{C}$ & 27.0 & 2.18 & 2.55 & 4.67 \\
\hline $\mathrm{R}_{\mathrm{W}} 100 \mathrm{C}$ & 31.0 & 2.24 & 2.64 & 4.88 \\
\hline
\end{tabular}

than $R_{U} 100 C$ after 28 -day curing period. The enhancement in strength of $R_{W} 100 \mathrm{C}$ concrete is due to the removal of weak and loose adhered mortar on the surface of recycled aggregate which makes it porous. This weak adhered mortar creates a weak interfacial bond between the cement mortar and recycled aggregate, which crucially affects compressive strength.

The 28 days compressive strength of cylinders is reported in Table 4 along with split tensile (7 and 28 days) for natural (R0C), unwashed $\left(\mathrm{R}_{\mathrm{U}} 50 \mathrm{C}\right.$ and $\left.\mathrm{R}_{\mathrm{U}} 100 \mathrm{C}\right)$, and washed recycled aggregates $\left(\mathrm{R}_{\mathrm{W}} 100 \mathrm{C}\right)$ mixes. The compressive strength of cylinders (28 days) is about $70-72 \%$ of cubes strength. The compressive strength of cylinder containing $\mathrm{R}_{\mathrm{U}} 50 \mathrm{C}, \mathrm{R}_{\mathrm{U}} 100 \mathrm{C}$, and $R_{W} 100 C$ mix is 80,92 , and $98 \%$, respectively, of natural aggregates mix (R0C). The results of split tensile strength presented in Table 4 show the same pattern of strength development as in case of compressive strength. Furthermore, it also shows that the rate of tensile strength development is more in early ages (7 days) in all mixes and was $86 \%$ for $\mathrm{R}_{\mathrm{U}} 100 \mathrm{C}$ washed and $90 \%$ for $\mathrm{R}_{\mathrm{W}} 100 \mathrm{C}$ of natural aggregates concrete. Flexural strength of prisms is determined on 28 days of curing and results (Table 4) show that maximum strength $4.98 \mathrm{MPa}$ has been given by concrete made using natural aggregate (R0C) mix as compared to the strength achieved 4.67 and $4.88 \mathrm{MPa}$ for $100 \%$ unwashed and washed recycled aggregates mix, respectively. The ratio of flexural strength of prisms to compressive strength of cubes is in the range of 10$12 \%$ and these values are about $15 \%$ lower if compared to the recommendations of ACI363R [38].

\subsection{Durability of Concrete}

3.3.1. Performance in Water. The results of water absorption (Table 5) depict that the water absorption of natural (R0C) and washed recycled aggregates concrete $\left(R_{W} 100 C\right)$ is significantly lower than unwashed recycled aggregates concrete $\left(R_{U} 50 \mathrm{C}\right.$ and $\left.R_{U} 100 \mathrm{C}\right)$ due to absence or removal of weak and old adhered mortar after washing. Water absorption of R0C and $\mathrm{R}_{\mathrm{W}} 100 \mathrm{C}$ is 3.50 and $4.80 \%$, respectively, while the same is 3.98 and $5.75 \%$ for $R_{U} 50 \mathrm{C}$ and $R_{U} 10 \mathrm{C}$, respectively. The bulk density of hardened concrete cubes was determined and results have been shown in Table 5 . It is observed that the density of $R_{U} 50 C, R_{U} 100 C$, and $R_{W} 100 C$ mix is 2436 , 2403 , and $2422 \mathrm{~kg} / \mathrm{m}^{3}$, respectively, as compared to density of natural aggregates (R0C) $2446 \mathrm{~kg} / \mathrm{m}^{3}$. The reason for
TABLE 5: Results of durability studies of hardened concrete cubes after 28-day curing period.

\begin{tabular}{lc}
\hline Test & Value \\
\hline Bulk density $\left(\mathrm{kg} / \mathrm{m}^{3}\right)$ & \\
R0C & 2446 \\
$\mathrm{R}_{\mathrm{U}} 50 \mathrm{C}$ & 2436 \\
$\mathrm{R}_{\mathrm{U}} 100 \mathrm{C}$ & 2403 \\
$\mathrm{R}_{\mathrm{W}} 100 \mathrm{C}$ & 2422 \\
Water absorption (\% at $48 \mathrm{~h})$ & \\
R0C & 3.50 \\
$\mathrm{R}_{\mathrm{U}} 50 \mathrm{C}$ & 3.98 \\
$\mathrm{R}_{\mathrm{U}} 100 \mathrm{C}$ & 5.75 \\
$\mathrm{R}_{\mathrm{W}} 100 \mathrm{C}$ & 4.80 \\
RCPT value (coulombs) & \\
$\mathrm{R}_{0 \mathrm{C}}$ & 2560 \\
$\mathrm{R}_{\mathrm{U}} 50 \mathrm{C}$ & 2620 \\
$\mathrm{R}_{\mathrm{U}} 100 \mathrm{C}$ & 2800 \\
$\mathrm{R}_{\mathrm{W}} 100 \mathrm{C}$ & 2650 \\
\hline
\end{tabular}

lower density of recycled aggregates may be attributed to the presence of porous adhered mortar on the surface of recycled aggregate [25].

3.3.2. Carbonation and Rapid Chloride Penetration Test (RCPT). All the concrete cubes kept in carbonation chamber exposed to carbon dioxide were tested after completion of 28 days by spray of phenolphthalein indicator. No change in colour of phenolphthalein was observed in mixes (R0C, $R_{U} 50 C, R_{U} 100 C$, and $R_{W} 100 C$ ) showing that no carbonation had taken place. The results of RCPT have been shown in Table 5 indicating that chloride permeability is moderate in mixes (R0C, $R_{U} 50 \mathrm{C}, \mathrm{R}_{\mathrm{U}} 100 \mathrm{C}$, and $\mathrm{R}_{\mathrm{W}} 100 \mathrm{C}$ mix) as the values of charges passed vary in the range of 2560-2800 coulombs. These values are meeting the criteria of chloride permeability as described in ASTM C1202 (1997) [32]. The chloride ion penetration is more 2800, 2620, and 2750 coulombs in concrete made from recycled aggregate as compared to control (2560 coulombs). However, the chloride permeability of concrete using washed recycled aggregate $\left(\mathrm{R}_{\mathrm{W}} 100 \mathrm{C}\right)$ is less in comparison to concrete using unwashed recycled aggregate $\left(R_{U} 100 C\right)$ due to removal of weak and porous adhered mortar after washing.

\section{Conclusions}

From the investigations carried out for mechanical and durability aspects of recycled coarse aggregates concrete, the following conclusion can be drawn:

(1) The physical and mechanical properties of recycled coarse aggregates used were inferior as compared to control (natural aggregate) and the properties get improved after washing due to removal of weak and porous adhered mortar.

(2) The compressive, tensile, and flexural strength of hardened concrete using natural aggregate was more 
than the concrete using recycled aggregates. A decrease of 7-19\% in compressive strength of recycled concrete has been observed with increase in recycled coarse content from 50 to $100 \%$. The strength of $\mathrm{R}_{\mathrm{W}} 100 \mathrm{C}$ concrete mix was $93 \%$ of control (R0C) and about $12.5 \%$ higher than the $\mathrm{R}_{\mathrm{U}} 100 \mathrm{C}$ concrete after 28-day curing period. Further, the results show that $100 \%$ washed recycled coarse aggregate may be utilized to achieve the compressive strength of higher grade.

(3) Improvement in the mechanical properties of hardened concrete using washed recycled aggregate is due to the removal of weak and porous mortar.

(4) The influence of different percentage of recycled aggregates on the durability of hardened concrete has been discussed. The results revealed that bulk density of control mix containing natural aggregates was higher with minimum water absorption as compared to recycled aggregates concrete. No carbonation has been observed in concrete using natural and recycled coarse aggregates after a period of 28 days of carbon dioxide exposure. RCPT results show moderate concrete permeability in all concrete mix $\left(\mathrm{R} 0 \mathrm{C}, \mathrm{R}_{\mathrm{U}} 100 \mathrm{C}\right.$, and $\left.\mathrm{R}_{\mathrm{W}} 100 \mathrm{C}\right)$.

\section{Conflict of Interests}

The authors declare that there is no conflict of interests regarding the publication of this paper.

\section{Acknowledgment}

The authors are thankful to Professor S. K. Bhattacharyya, Director, CSIR-CBRI, Roorkee, India, for his permission to publish the present work.

\section{References}

[1] M. Sharholy, K. Ahmad, G. Mahmood, and R. C. Trivedi, "Municipal solid waste management in Indian cities-a review," Waste Management, vol. 28, no. 2, pp. 459-467, 2008.

[2] A. Pappu, M. Saxena, and S. R. Asolekar, "Solid wastes generation in India and their recycling potential in building materials," Building and Environment, vol. 42, no. 6, pp. 2311-2320, 2007.

[3] A. D. Bhide and A. V. Shekdar, "Solid waste management in Indian urban centers," International Solid Waste Association Times (ISWA), no. 1, pp. 26-28, 1998.

[4] A. Mujahid and A. Zaidi, "Assessment of recycled aggregate concrete," Modern Applied Science, vol. 3, no. 10, pp. 47-54, 2009.

[5] A. Rao, K. N. Jha, and S. Misra, "Use of aggregates from recycled construction and demolition waste in concrete," Resources, Conservation and Recycling, vol. 50, no. 1, pp. 71-81, 2007.

[6] S. Marinković, V. Radonjanin, M. Malešev, and I. Ignjatović, "Comparative environmental assessment of natural and recycled aggregate concrete," Waste Management, vol. 30, no. 11, pp. 2255-2264, 2010.

[7] K. K. Sagoe-Crentsil, T. Brown, and A. H. Taylor, "Performance of concrete made with commercially produced coarse recycled concrete aggregate," Cement and Concrete Research, vol. 31, no. 5, pp. 707-712, 2001.

[8] ECCO, Recycling Concrete and Masonry. Information Bulletin EV 22, Environmental Council of Concrete Organizations, Skokie, Ill, USA, 1999.

[9] Construction Materials Recycling Association, Concrete Recycling.org, 2013.

[10] V. W. Y. Tam, "Comparing the implementation of concrete recycling in the Australian and Japanese construction industries," Journal of Cleaner Production, vol. 17, no. 7, pp. 688-702, 2009.

[11] Y. Dosho, "Development of a sustainable concrete waste recycling system: application of recycled aggregate concrete produced by aggregate replacing method," Journal of Advanced Concrete Technology, vol. 5, no. 1, pp. 27-42, 2007.

[12] European Aggregates Association, Annual Review 2011-2012, European Aggregates Association, Brussels, Belgium, 2012.

[13] DIN, "Aggregate for mortar and concrete-part 100: recycled aggregates," DIN 4226-100, Deutsches Institut für Normung, Beuth, Berlin, Germany, 2002.

[14] Japanese Industrial Standard, "Recycled aggregate for concrete Class 'H”, JIS A 5021:2011, Japanese Industrial Standard, 2011.

[15] JIS A 5023, Recycled Concrete Using Recycled Aggregate Class "L", Japanese Industrial Standards, Tokyo, Japan, 2012.

[16] DG/TJ07-008, Technical Code of Application of Recycled Aggregate Concrete, Shanghai Construction Standard Society (SCSS), Shanghai, China, 2007.

[17] WBTC 12, "Specifications facilitating the use of recycled aggregates," Works Bureau Technical Circular 12/2002, Hong Kong SAR Government, Hong Kong, 2002.

[18] British Standards Institution, BS EN 12620: Aggregates for Concrete, British Standards Institution, London, UK, 2013.

[19] Bureau of Indian Standards, IS 8112: Specification for 43 Grade Ordinary Portland Cement, Bureau of Indian Standards, New Delhi, India, 1989.

[20] IS 383, Specification for Coarse and Fine Aggregates from Natural Sources for Concrete, Bureau of Indian Standards, New Delhi, India, 1970.

[21] IS 2386, Methods of Test for Aggregates for Concrete Part I-IV, Bureau of Indian Standards, 1963.

[22] K. K. Sagoe-Crentsil, T. Brown, and A. H. Taylor, "Performance of concrete made with commercially produced coarse recycled concrete aggregate," Cement and Concrete Research, vol. 31, no. 5, pp. 707-712, 2001.

[23] M. Etxeberria, E. Vázquez, A. Marí, and M. Barra, "Influence of amount of recycled coarse aggregates and production process on properties of recycled aggregate concrete," Cement and Concrete Research, vol. 37, no. 5, pp. 735-742, 2007.

[24] IS:10262, Recommended Guidelines for Concrete Mix Design, Bureau of Indian Standards, 1982.

[25] S. Ismail and M. Ramli, "Engineering properties of treated recycled concrete aggregate (RCA) for structural applications," Construction and Building Materials, vol. 44, no. 7, pp. 464-476, 2013.

[26] Bureau of Indian Standards, IS:1199: Methods of Sampling and Analysis of Concrete, Bureau of Indian Standards, New Delhi, India, 1959.

[27] American Society for Testing and Materials, "Standard test method for density, absorption, and voids in hardened concrete," ASTM C642-06, American Society for Testing and Materials, 2002. 
[28] Bureau of Indian Standards, IS:516: Method of Tests for Strength of Concrete, Bureau of Indian Standards, New Delhi, India, 1959.

[29] IS: 5816, Method of Test Splitting Tensile Strength of Concrete, Bureau of Indian Standards, New Delhi, India, 1999.

[30] V. G. Papadakis, C. G. Vayenas, and M. N. Fardis, "Fundamental modeling and experimental investigation of concrete carbonation," ACI Materials Journal, vol. 88, no. 4, pp. 363-373, 1991.

[31] RILEM TC, "CPC18 measurement for hardened concrete carbonated depth, RILEM recommendations for the testing and use of construction materials RILEM," Bagneux, France, 1994.

[32] ASTM C1202, Test Method for Electrical Indication of Concrete Ability to Resist Chloride Ion Penetration, American Society for Testing and Materials, 1997.

[33] A. K. Padmini, K. Ramamurthy, and M. S. Mathews, "Influence of parent concrete on the properties of recycled aggregate concrete," Construction and Building Materials, vol. 23, no. 2, pp. 829-836, 2009.

[34] M. Chakradhara Rao, S. K. Bhattacharyya, and S. V. Barai, "Influence of field recycled coarse aggregate on properties of concrete," Materials and Structures, vol. 44, no. 1, pp. 205-220, 2011.

[35] C. S. Poon, Z. H. Shui, and L. Lam, "Effect of microstructure of ITZ on compressive strength of concrete prepared with recycled aggregates," Construction and Building Materials, vol. 18, no. 6, pp. 461-468, 2004.

[36] V. W. Y. Tam and C. M. Tam, "Parameters for assessing recycled aggregate and their correlation," Waste Management and Research, vol. 27, no. 1, pp. 52-58, 2009.

[37] W. H. Kwan, M. Ramli, K. J. Kam, and M. Z. Sulieman, "Influence of the amount of recycled coarse aggregate in concrete design and durability properties," Construction and Building Materials, vol. 26, no. 1, pp. 565-573, 2012.

[38] ACI363R, "State of the art report on high strength concrete," ACI committee 363, 1997. 

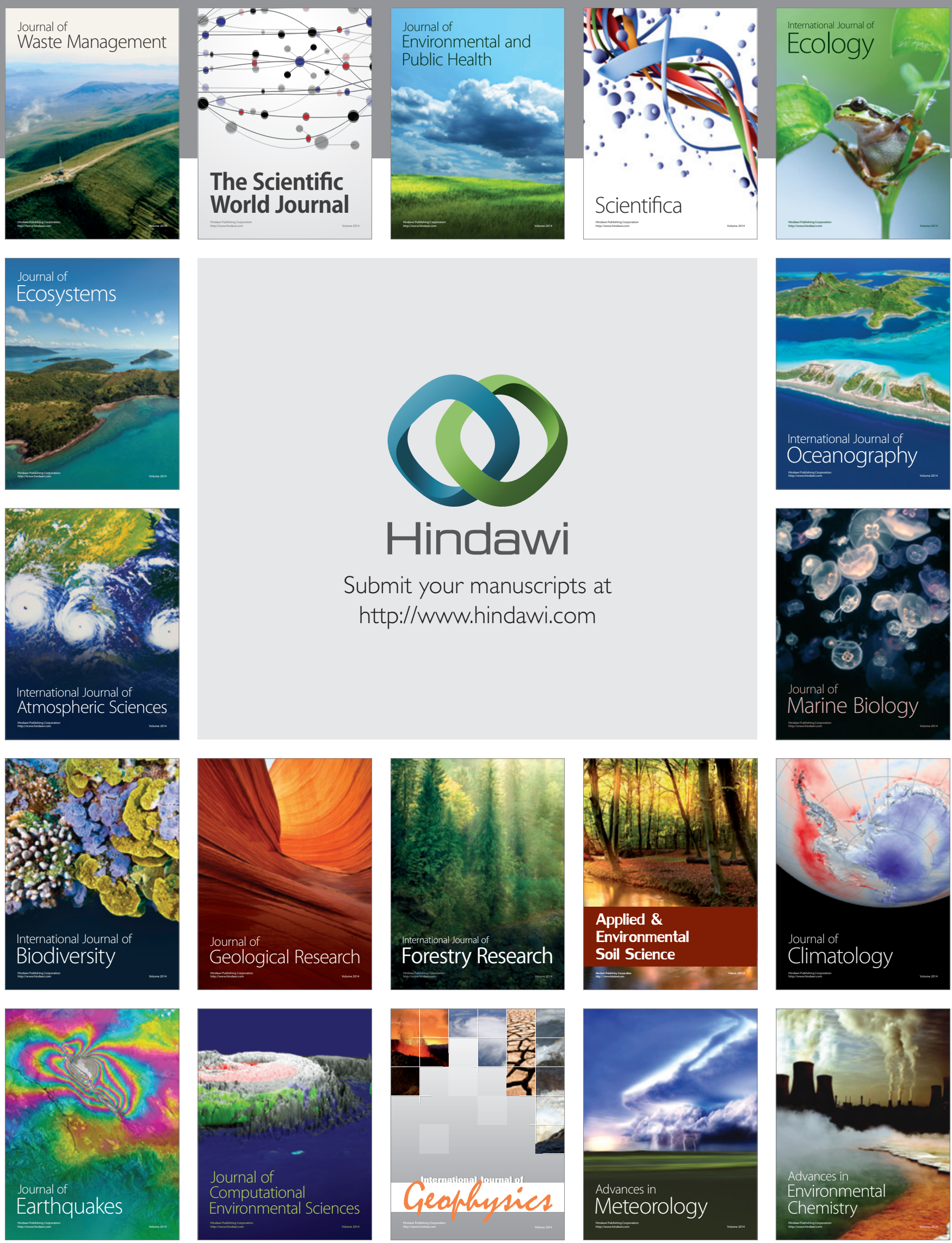